\title{
Ytterbium acetate as a particulate-phase digesta-flow marker
}

\author{
BY R. C. SIDDONS, J. PARADINE, D. E. BEEVER AND P. R. CORNELL \\ The Grassland Research Institute*, Hurley, Maidenhead, Berks SL6 5LR
}

(Received 8 November 1984 - Accepted 24 April 1985)

1. The ability of ytterbium acetabe $(\mathrm{Yb}$ acetate) to fulfil the requirements of a particulate-phase digesta-flow marker in a dual-phase marker system, and of the indigestible acid-detergent-fibre fraction of the feed (IADF) to act as a digesta flow marker, were examined using six mature wether sheep given a diet of dried grass $(1 \mathrm{~kg}$ dry matter (DM)/d).

2. CrEDTA was continuously infused ( $240 \mathrm{mg}$ chromium/d) into the rumen of all sheep and $\mathrm{Yb}$ acetate was also continuously infused $(100 \mathrm{mg} \mathrm{Yb} / \mathrm{d})$ into the rumen of three of the sheep. At this level of infusion the equilibrium concentration of $\mathrm{Yb}$ in rumen, duodenal and ileal digesta and in faeces could be reliably measured by atomic absorption spectrometry.

3. Estimates of faecal DM excretion based on either Yb or IADF did not differ $(P>0.05)$ from that determined by total collection, whereas estimates based on $\mathrm{Cr}$ were significantly $(P<0.05)$ lower. Urinary excretion accounted for $3.1 \%$ of the infused $\mathrm{Cr}$ but no $\mathrm{Yb}$ was detected in urine. Estimates of ileal $\mathrm{DM}$ flow, assuming total marker recovery, were similar $(P>0.05)$ with all three markers, whereas the estimate of duodenal DM flow based on IADF was lower $(P<0.05)$ than the estimates based on either $\mathrm{Cr}$ or $\mathrm{Yb}$.

4. Compared with the infusion of $\mathrm{Cr}$ alone, the infusion of $\mathrm{Cr}$ and $\mathrm{Yb}$ had no effect $(P>0.05)$ on nutrient flows at the duodenum, ileum and in faeces nor on microbial degradative activity, volatile fatty acid production and $\mathrm{N}$ metabolism in the rumen.

5. Polyester bag and in vitro studies showed that pre-labelling the dried grass with up to $285 \mathrm{mg} \mathrm{Yb} / \mathrm{g} \mathrm{DM}$ did not affect its susceptibility to microbial degradation.

6. The $\mathrm{Yb}$ in rumen, duodenal and ileal digesta was predominantly $(>90 \%)$ associated with the particulate matter but was not uniformly distributed and its concentration increased as particle size decreased.

7. The use of CrEDTA and $\mathrm{Yb}$ acetate as a dual-phase marker system proved more reliable in estimating 'true' duodenal flow than the use of the individual markers when the digesta sample was unrepresentative.

Net absorption from or secretion into the different parts of the gastrointestinal tract can be determined by measuring the quantity and composition of digesta flowing past cannulas inserted at various points along the tract (MacRae, 1975). To avoid the problems associated with total digesta collection, estimates of flow are usually obtained from the relation between the equilibrium concentration of a marker in a sample of the digesta and the amount of marker continuously infused or ingested. When re-entrant cannulas are used in conjunction with automatic sampling machines (Canaway \& Thomson, 1977), which allow continuous sampling and so provide a representative sample of the total digesta flow, only one marker is required. However, because digesta flow from the rumen is a discontinuous process with the fluid and particulate phases flowing at different rates, the use of a single marker with spot sampling from either re-entrant cannulas or simple ' $T$ '-shaped cannulas may give erroneous estimates of flow, due to unrepresentative sampling of the digesta in terms of a preferential selection of either of the two phases. Faichney (1975a) showed that this problem could be overcome by using two markers in a dual-phase marker system.

CrEDTA is the most commonly used liquid-phase marker and ruthenium phenanthroline the most commonly used particulate-phase marker. Both the radioactive (Tan et al. 1971) and non-radioactive (Beever et al. 1978) forms of Ru have been used. However, the practical applications of the former are limited to controlled indoor studies, whilst in our experience the latter was found not to be totally satisfactory because of the difficulties encountered in the analysis of Ru by X-ray fluorescence spectrometry at the relatively low levels in digesta imposed by its toxic effect on rumen micro-organisms (Evans et al. 1977; Beever et al. 1978).

* Now The Animal and Grassland Research Institute. 
A number of rare earth elements have also been shown to bind to particulate matter (Hartnell \& Satter, 1979; Crooker et al. 1982; Ellis et al. 1982) but their application is limited because of the need to use either the radioactive forms of the elements or the requirement for specialized analysis such as neutron activaton. In this respect ytterbium has the advantage that it can be measured at relatively low levels by atomic absorption spectrometry (Teeter et al. 1979). Therefore, the present study was undertaken to examine whether $\mathrm{Yb}$ acetate, when used in conjunction with CrEDTA, would fulfil the requirements of a particulate-phase marker in a dual-phase marker system, i.e. that it would be associated predominantly with particulate matter, would be non-absorbable, and could be accurately measured in digesta and faeces when infused at a rate which did not affect the digestive processes (Engelhardt, 1974). The possibility of using the indigestible acid-detergent-fibre fraction (IADF) of the feed (Penning \& Johnson, 1983) as a digesta-flow marker was also examined.

\section{EXPERIMENTAL}

\section{In vivo study}

Six Suffolk $\times$ halfbred wethers were used, weighing $57-62 \mathrm{~kg}$ and each fitted with a rumen cannula and re-entrant cannulas in the proximal duodenum and distal ileum. They were housed individuallly in metabolism cages and allowed free access to water and mineral lick. Each sheep was given a diet of cobbed dried grass (Lolium perenne $\mathrm{cv}$. Melle, $1 \mathrm{~kg}$ dry matter (DM)/d) using automatic feeders which dispensed the feed in hourly portions. Before the start of the experiment the dried grass was given for 3 weeks during which 'donor' duodenal and ileal digesta were collected to be used subsequently to replace digesta removed during the experiment. After the diet adaptation period, CrEDTA, prepared according to the procedure of Binnerts et al. (1968), was continuously infused ( $240 \mathrm{mg} \mathrm{Cr} / \mathrm{d}$ ) into the rumen of all sheep, and ytterbium acetate ( $\mathrm{Yb}$ acetate) dissolved in distilled water was also continuously infused $(100 \mathrm{mg} \mathrm{Yb} / \mathrm{d})$ into the rumen of three of the sheep. $\mathrm{Yb}$ acetate was used in preference to $\mathrm{Yb}$ chloride because the latter was insoluble above $\mathrm{pH}$ 4.0 , although when the $\mathrm{Yb}$ acetate and CrEDTA were mixed together a precipitate formed on standing. Therefore, the two markers were infused via separate infusion lines. The extent of precipitate formation could be reduced by using the crystallized lithium salt of CrEDTA (Uden et al. 1980). The markers were continuously infused throughout the study. During the first 3 weeks of the infusions, the total faeces and urine excreted were collected on a daily basis and bulked samples prepared for each of the last 2 weeks. In the fourth week, polyester-bag studies were undertaken in which the degradation of samples of the dried grass, maize, soya-bean meal and also of dried grass which had been labelled with $\mathrm{Yb}$ was measured. The $\mathrm{Yb}$ labelled dried grass was prepared by incubation in $\mathrm{Yb}$ acetate solution of differing concentrations for $24 \mathrm{~h}$ at $39^{\circ}$, followed by repeated washing with water to remove unbound $\mathrm{Yb}$. Samples of the feedstuffs $(5 \mathrm{~g} \mathrm{DM})$ which had been ground through a $3 \mathrm{~mm}$ sieve were incubated in duplicate in polyester bags $(190 \mathrm{~mm} \times 120 \mathrm{~mm}, 43 \mu \mathrm{m}$ pore size) in the rumen and removed after $4,8,12,16,24$ and $48 \mathrm{~h}$. They were then washed by gentle squeezing in cold running water for $20 \mathrm{~min}$ and the DM and nitrogen remaining measured. The loss of DM and $\mathrm{N}(y)$ with time $(t)$ was fitted to the equation

$$
y=a+b\left(1-\mathrm{e}^{-k t}\right)
$$

where $a+b$ represents the potentially degradable fraction consisting of a soluble 'instantlydegradable' component $(a)$ and insoluble component $(b)$ degraded at a constant rate $(k)$. In the fifth week, volatile fatty acid (VFA) production rate in the rumen was determined according to the procedure of Weller et al. (1967) using a $24 \mathrm{~h}$ continuous intraruminal 
infusion $(4 \mu \mathrm{Ci} / \mathrm{h})$ of sodium $\left[1-{ }^{14} \mathrm{C}\right]$ acetate and measuring the ${ }^{14} \mathrm{C}$ specific radioactivity of the VFA in rumen-fluid samples taken hourly during the last $8 \mathrm{~h}$ of the infusion. This was followed by the manual collection of ileal digesta over a $12 \mathrm{~h}$ period. In the sixth week, $\left({ }^{15} \mathrm{NH}_{4}\right)_{2} \mathrm{SO}_{4}\left(96\right.$ atoms ${ }^{15} \mathrm{~N} / 100$ atoms $\left.\mathrm{N}\right)$ was continuously infused $\left(40 \mathrm{mg}{ }^{15} \mathrm{~N} / \mathrm{d}\right)$ into the rumen for $3 \mathrm{~d}$, and duodenal digesta were collected during the last $2 \mathrm{~d}$ using automatic sampling machines (Canaway \& Thomson, 1977). The machines were designed to remove a representative sample of the total digesta flowing through the cannula during the collection period. Rumen-fluid samples were also taken during the last $2 \mathrm{~d}$ of the ${ }^{15} \mathrm{~N}$ infusion for measurement of ammonia $\mathrm{N}$ enrichment, whilst rumen $\mathrm{pH}$, VFA and ammonia content were measured in six rumen-fluid samples taken on a weekly basis during the marker infusions. After completion of the ${ }^{15} \mathrm{~N}$ infusion, the $\mathrm{Cr}$ and $\mathrm{Yb}$ infusions were terminated and the fractional outflow rate of fluid from the rumen determined from the decrease in the $\mathrm{Cr}$ concentration in rumen-fluid samples taken over a $36 \mathrm{~h}$ period.

\section{Sample preparation}

Rumen-fluid samples were acidified $(\mathrm{pH}<2)$ and stored frozen. Samples of faeces, duodenal and ileal digesta were freeze-dried. A microbial fraction was prepared from duodenal digesta by differential centrifugation (Siddons et al. 1982) and freeze-dried. Separation of the soluble and particulate matter in fresh samples of rumen, duodenal and ileal digesta was achieved by high-speed centrifugation at $20000 \mathrm{~g}$ for $30 \mathrm{~min}$ and fractionation of the particulate matter by wet sieving. Part of the duodenal digesta collected during the 3rd day of the ${ }^{15} \mathrm{~N}$ infusion was used to prepare samples of 'unrepresentative' digesta in the following manner: after centrifuging the digesta at $1500 \mathrm{~g}$ for $10 \mathrm{~min}$, part of the upper layer was removed and added to the original digesta to give a lowparticulate-matter sample (LP) whilst the remainder of the material which had been centrifuged was re-mixed to give a high-particulate-matter sample (HP). Samples of the whole unrepresentative digesta and of their respective subsamples, prepared by centrifuging the unrepresentative digesta sample at $1500 \mathrm{~g}$ for $20 \mathrm{~min}$ and discarding the upper layer, were freeze-dried.

\section{In vitro study}

Ground samples of the dried grass $(0.5 \mathrm{~g} \mathrm{DM})$ which had been pre-labelled with $\mathrm{Yb}$ were incubated in duplicate with rumen fluid (10 ml) and buffer (McDougall $(1948) ; 40 \mathrm{ml})$ at $39^{\circ}$ under an atmosphere of $\mathrm{CO}_{2}$, and the VFA and ammonia concentrations in the incubation mixture measured at $0,2,4,6$ and $24 \mathrm{~h}$. Incubations were also carried out using the dried grass labelled with $0 \mu \mathrm{g} \mathrm{Yb} / \mathrm{g} \mathrm{DM}$ and with different levels of $\mathrm{Yb}$ acetate added to the incubation mixture.

\section{Analytical methods}

Organic matter (OM) was determined by ashing at $550^{\circ}$ for $16 \mathrm{~h}$, total $\mathrm{N}$ by Kjeldahl digestion and ammonia by an automated colorimetric procedure (Gehrke et al. 1968). The VFA was measured by gas-solid chromatography at $160^{\circ}$ with Chromosorb 101 as the stationary phase. ${ }^{15} \mathrm{~N}$ enrichment was measured by isotope-ratio mass spectrometry, after isolation of the nitrogenous fraction as ammonium sulphate by steam distillation (Pruden et al. 1985). Cellulose was determined by the method of Crampton \& Maynard (1938) and IADF as described by Penning \& Johnson (1983). Cr was determined by atomic absorption spectrometry using a nitrous oxide-acetylene flame. The $\mathrm{Cr}$ content of rumen-fluid samples was measured by direct aspiration whereas digesta and faeces were extracted by a procedure similar to that described by Christian \& Coup (1954): $0.5 \mathrm{~g}$ sample was ashed in a conical flask at $500^{\circ}$ for $16 \mathrm{~h}$ and $6 \mathrm{ml}$ digestion acid $(250 \mathrm{ml}$ orthophosphoric acid $(880 \mathrm{~g} / \mathrm{l}), 50 \mathrm{ml}$ 
manganese sulphate $(100 \mathrm{~g} / \mathrm{l}), 250 \mathrm{ml}$ concentrated sulphuric acid/l) added to the ash. The mixture was heated to boiling and $3 \mathrm{ml}$ potassium bromate solution $(45 \mathrm{~g} / 1)$ added. Heating was continued until the solution turned a deep purple and white fumes evolved after which the mixture was heated for a further $3 \mathrm{~min}$ and then allowed to cool. After diluting to $100 \mathrm{ml}$ with distilled water, the $\mathrm{Cr}$ content was measured using standards of potassium dichromate dissolved in digestion acid $(60 \mathrm{ml} / \mathrm{l})$. The $\mathrm{Cr}$ content of the infusion solutions was determined by addition to blank digesta and faeces samples. Y $b$ was measured by atomic absorption spectrometry using a nitrous oxide-acetylene flame after extraction by a procedure similar to that described by Ellis et al. (1981): digesta and faeces ( $0.5 \mathrm{~g} \mathrm{DM})$ in conical flasks were dried at $100^{\circ}$ overnight and ashed at $500^{\circ}$ for $16 \mathrm{~h}$. The ash was extracted by shaking for $1 \mathrm{~h}$ with $20 \mathrm{ml}$ acid solution containing $2 \cdot 25 \mathrm{M}$-hydrochloric acid, $2 \cdot 25 \mathrm{M}$-nitric acid and $1 \mathrm{mg} \mathrm{K}$ as potassium chloride $/ \mathrm{ml}$. The extract was centrifuged and the $\mathrm{Yb}$ content of the supernatant fraction measured. Standards were prepared using blank digesta or faeces, containing no $\mathrm{Yb}: 0.5 \mathrm{~g} \mathrm{DM}$ was wetted with $4 \mathrm{ml}$ distilled water, $1 \mathrm{ml} \mathrm{Yb}$ acetate solution added and, after mixing, dried at $100^{\circ}$ overnight and extracted as described previously.

\section{Statistical analysis}

Within-animal comparisons were made using a paired $t$ test and analysis of variance was used for between-animal comparisons.

\section{RESULTS}

After the start of the continuous intra-ruminal infusion of the markers, the faecal $\mathrm{Cr}$ concentration increased more rapidly than the $\mathrm{Yb}$ concentration and reached a plateau by the 5th day, whilst the plateau $\mathrm{Yb}$ concentration was not reached until $1 \mathrm{~d}$ later. Estimates of faecal DM excretion based on the plateau $\mathrm{Cr}$ and $\mathrm{Yb}$ concentrations and also on the faecal IADF concentration, and assuming total recovery of the markers, are presented in Table 1 . The $\mathrm{Yb}$ - and IADF-based estimates did not differ significantly $(P>0.05)$ from each other, nor from that determined by total faeces collecton, whereas the estimates based on $\mathrm{Cr}$ were significantly $(P<0.05)$ lower than that determined by total collection. The Cr-based estimates were also significantly $(P<0.05)$ lower than the Yb-based estimates but did not differ significantly $(P>0.05)$ from those based on IADF. Urinary $\mathrm{Cr}$ excretion accounted for 3.1 (SE 0.42$) \%(n$ 6) of the $\mathrm{Cr}$ infused but no $\mathrm{Yb}$ was detected in the urine.

Estimates of the amount of DM flowing at the duodenum and ileum, based on the $\mathrm{Cr}$, $\mathrm{Yb}$ and IADF concentrations in digesta in relation to the amount of each individual marker infused or ingested, are also presented in Table 1. Ileal flows did not differ significantly $(P>0.05)$ between markers, and duodenal flows based on $\mathrm{Cr}$ or $\mathrm{Yb}$ were also similar $(P>0.05)$ whereas those based on IADF were significantly $(P<0.05)$ lower.

Nutrient flows along the gastrointestinal tract of the sheep receiving a continuous intraruminal infusion of CrEDTA and those receiving CrEDTA plus $\mathrm{Yb}$ acetate are shown in Table 2. Faecal flows relate to total collection, whilst flows at the duodenum and ileum are based on infused $\mathrm{Cr}$ corrected for the loss between rumen and faeces, assuming 0.4 of the total loss occurred before the duodenum and 0.2 in the small intestine (Faichney, $1975 b$ ). There were no significant $(P>0.05)$ differences between the two groups of sheep in the quantities of $\mathrm{OM}$, cellulose and non-ammonia- $N$ flowing at the duodenum and ileum and excreted in the faeces. Results for rumen measurements in the groups of sheep are presented in Table 3. Although total VFA concentration was lower $(P<0.05)$ in the sheep receiving $\mathrm{Yb}$, the rate of VFA production and the molar proportions of the individual VFA did not 
Table 1. Estimates of dry matter flow $(g / d)$ at the duodenum and ileum and excreted in faeces based on the chromium, ytterbium and indigestible acid-detergent-fibre (IDAF) content of digesta and faeces

(Mean values with their standard errors, no. of sheep given in parentheses)

\begin{tabular}{|c|c|c|c|c|c|c|}
\hline & \multicolumn{2}{|c|}{$\begin{array}{l}\mathrm{Cr} \\
(6)\end{array}$} & \multicolumn{2}{|c|}{$\begin{array}{l}\mathrm{Yb} \\
(3)\end{array}$} & \multicolumn{2}{|c|}{$\begin{array}{c}\text { IADF } \\
(6)\end{array}$} \\
\hline & Mean & $\mathrm{SE}$ & Mean & SE & Mean & $\mathrm{SE}$ \\
\hline Duodenal flow & 546 & $14 \cdot 3$ & 563 & $19 \cdot 9$ & 468 & 18.5 \\
\hline Ileal flow & 342 & $20 \cdot 4$ & 359 & $22 \cdot 3$ & 332 & $7 \cdot 9$ \\
\hline Faecal excretion & 233 & 3.0 & 219 & $2 \cdot 2$ & 231 & $5 \cdot 5$ \\
\hline Recovery in faeces $(\%)$ & 94.7 & 1.89 & $103 \cdot 9$ & 3.76 & $95 \cdot 9$ & $3 \cdot 24$ \\
\hline
\end{tabular}

Table 2. Nutrient flows $(\mathrm{g} / \mathrm{d})$ along the gastrointestinal tract of sheep receiving continuous intraruminal infusions of either CrEDTA or CrEDTA plus ytterbium acetate

(Mean values for three sheep)

\begin{tabular}{llccc}
\hline & & $\mathrm{Cr}$ & $\mathrm{Cr}+\mathrm{Yb}$ & SEM \\
\hline \multirow{2}{*}{ Organic matter: } & Intake & 907 & 907 & - \\
& At duodenum & 397 & 407 & $15 \cdot 1$ \\
& At ileum & 240 & 270 & $11 \cdot 7$ \\
& In faeces & 168 & 177 & $4 \cdot 4$ \\
Cellulose: & Intake & 229 & 229 & - \\
& At duodenum & 55 & 56 & $4 \cdot 7$ \\
& At ileum & 46 & 54 & 5.6 \\
& In faeces & 34 & 35 & $1 \cdot 7$ \\
Non-amonia-N: & Intake & $19 \cdot 2$ & $19 \cdot 2$ & -7.95 \\
& At duodenum & 24.9 & $25 \cdot 7$ & 0.95 \\
& At ileum & 8.8 & $10 \cdot 1$ & 0.58 \\
& In faeces & 6.7 & 7.2 & 0.20 \\
\hline
\end{tabular}

differ significantly $(P>0 \cdot 05)$ between the two groups. Rumen fluid volume was also lower $(P<0.05)$ in the sheep receiving $\mathrm{Yb}$, whilst rumen fluid dilution rate tended to be higher, but this difference was not significant $(P>0.05)$. Rumen ammonia concentration, irreversible loss rate, outflow in fluid, net incorporation into microbial $\mathrm{N}$ and apparent absorption were all similar $(P>0.05)$ in the two groups of sheep as was the amount of microbial $\mathrm{N}$ flowing at the duodenum, the efficiency of microbial $\mathrm{N}$ synthesis, the entry of endogenous $\mathrm{N}$ to the forestomachs and the proportion of microbial $\mathrm{N}$ and duodenal ammonia derived from the rumen ammonia pool.

The loss of DM or $\mathrm{N}$ when samples of either the dried grass, maize or soya-bean meal were incubated in the rumen of the sheep receiving the infusion of CrEDTA was similar to that when incubated in the rumen of the sheep receiving CrEDTA plus $\mathrm{Yb}$ acetate. Thus, for each feedstuff there was no significant $(P>0.05)$ effect of $\mathrm{Yb}$ infusion on either the proportion of the total DM or $\mathrm{N}$ which was potentially degradable nor on the fractionation of the potentially degradable material into its soluble and insoluble components. The degradation rate constants of the insoluble degradable component are presented in Table 4. For both the dried grass and the maize, the rate of DM degradation and also the rate of $\mathrm{N}$ degradation were very similar $(P>0.05)$ when determined in the two groups of sheep, whereas for soya-bean meal the rates of DM and $\mathrm{N}$ degradation tended to be higher in the 
Table 3. Volatile fatty acid production and nitrogen metabolism in the rumen of sheep receiving continuous intraruminal infusions of either CrEDTA or CrEDTA plus ytterbium acetate

(Mean values for three sheep)

\begin{tabular}{|c|c|c|c|}
\hline & $\mathrm{Cr}$ & $\mathrm{Cr}+\mathrm{Yb}$ & SEM \\
\hline Rumen fluid volume (1) & 7.96 & 6.01 & $0.46^{*}$ \\
\hline Fluid dilution rate $(/ \mathrm{h})$ & 0.053 & 0.084 & 0.010 \\
\hline $\mathrm{pH}$ & $6 \cdot 3$ & 6.6 & $0 \cdot 11$ \\
\hline \multicolumn{4}{|l|}{ Volatile fatty acids: } \\
\hline Production rate $(\mathrm{mol} / \mathrm{d})$ & $6 \cdot 4$ & $6 \cdot 0$ & 0.60 \\
\hline Total concentration (mmol/l) & $107 \cdot 5$ & $89 \cdot 2$ & $3 \cdot 38^{*}$ \\
\hline \multicolumn{4}{|l|}{ Molar proportions: } \\
\hline Acetate & 0.68 & 0.69 & 0.018 \\
\hline Propionate & 0.21 & 0.21 & 0.011 \\
\hline Butyrate & $0 \cdot 11$ & $0 \cdot 10$ & 0.014 \\
\hline \multicolumn{4}{|l|}{ Ammonia-N: } \\
\hline Irreversible loss rate $(\mathrm{g} / \mathrm{d})$ & 16.9 & $17 \cdot 5$ & 1.95 \\
\hline Concentration $(\mathrm{mg} / \mathrm{l})$ & 115 & 98 & $8 \cdot 20$ \\
\hline Outflow in fluid $(\mathrm{g} / \mathrm{d})$ & $1 \cdot 1$ & $1 \cdot 2$ & $0 \cdot 12$ \\
\hline Net incorporation by microbes $(\mathrm{g} / \mathrm{d})$ & $10 \cdot 2$ & $12 \cdot \overline{6}$ & $1 \cdot 36$ \\
\hline Apparent absorption (g/d) & 5.5 & $3 \cdot 7$ & 0.90 \\
\hline \multicolumn{4}{|l|}{ Microbial N synthesis: } \\
\hline $\mathrm{g} / \mathrm{d}$ & $14 \cdot 5$ & $16 \cdot 0$ & $1 \cdot 15$ \\
\hline $\mathrm{g} / \mathrm{kg}$ OMADR & 28.7 & $32 \cdot 6$ & $2 \cdot 54$ \\
\hline $\begin{array}{l}\text { Proportion of microbial } \mathrm{N} \text { from } \\
\text { rumen ammonia }\end{array}$ & 0.69 & 0.76 & 0.09 \\
\hline $\begin{array}{l}\text { Proportion of duodenal ammonia } \\
\text { from rumen ammonia }\end{array}$ & 0.59 & 0.54 & 0.06 \\
\hline Endogenous $N$ transfer to rumen $(\mathrm{g} / \mathrm{d})$ & $12 \cdot 0$ & 11.7 & $1 \cdot 20$ \\
\hline
\end{tabular}

OMADR, organic matter apparently digested in the rumen.

Statistical significance of difference between infusions: ${ }^{*} P<0.05$.

Table 4. Degradation rate constants for dry matter $(D M)$ and nitrogen when different feedstuffs were incubated in polyester bags in the rumen of sheep receiving continuous intraruminal infusions of either CrEDTA or CrEDTA plus ytterbium acetate

(Mean values for three sheep)

\begin{tabular}{|c|c|c|c|c|}
\hline & & $\mathrm{Cr}$ & $\mathrm{Cr}+\mathrm{Yb}$ & SEM \\
\hline \multirow[t]{2}{*}{ Dried grass: } & DM & 0.081 & 0.088 & 0.016 \\
\hline & $\mathrm{N}$ & 0.091 & 0.092 & 0.014 \\
\hline \multirow[t]{2}{*}{ Maize: } & DM & 0.079 & 0.071 & 0.005 \\
\hline & $\mathrm{N}$ & 0.036 & 0.036 & 0.006 \\
\hline \multirow[t]{2}{*}{ Soya-bean meal: } & DM & $0 \cdot 106$ & 0.159 & 0.023 \\
\hline & $\mathrm{N}$ & $0 \cdot 122$ & $0 \cdot 171$ & 0.030 \\
\hline
\end{tabular}

sheep receiving $\mathrm{Yb}$ but the differences were not significant $(P>0.05)$. Pre-labelling the dried grass with different amounts of $\mathrm{Yb}(0,40,75,160$ and $283 \mathrm{mg} / \mathrm{kg} \mathrm{DM})$ was also found to have no effect on the rate and extent of DM and $\mathrm{N}$ degradation during incubation in polyester bags in the rumen. Similarly, in vitro studies showed no effect of either pre-labelling the dried grass with the different levels of $\mathrm{Yb}$ or addition of equivalent amounts of $\mathrm{Yb}$ to the incubation mixture on either OM digestibility as measured by the Tilley \& Terry (1963) technique, nor on VFA and ammonia production during incubation with rumen fluid. The concentrations of acetate, propionate and butyrate, when corrected for the production in 
Table 5. Effect of ytterbium on the in vitro organic matter $(O M)$ digestibility of the feed and volatile fatty acid (VFA) and ammonia production during a $24 \mathrm{~h}$ incubation of feed and rumen fluid

(Results corrected for VFA and ammonia production in blank incubations containing no feed)

\begin{tabular}{lccc}
\hline Yb (mg/kg feed DM) . & 0 & $283^{*}$ & $283 \dagger$ \\
\hline OM digestibility & 59 & 59 & 60 \\
VFA production (mol/g feed) & 1.90 & 1.95 & $1 \cdot 80$ \\
Acetate & $0 \cdot 70$ & $0 \cdot 75$ & $0 \cdot 70$ \\
Propionate & 0.20 & $0 \cdot 20$ & $0 \cdot 20$ \\
Butyrate & $-21 \cdot 2$ & $-20 \cdot 6$ & $-18 \cdot 0$ \\
Ammonia-N production (mg/g feed) & -
\end{tabular}

DM, dry matter.

* Feed prelabelled.

$\uparrow$ Added to incubation mixture.

Table 6. The distribution of dry matter (DM) and ytterbium in rumen, duodenal and ileal digesta of sheep receiving continuous intraruminal infusions of CrEDTA plus Yb acetate

(Mean values with their standard errors for three sheep)

\begin{tabular}{|c|c|c|c|c|c|c|c|c|}
\hline & \multicolumn{6}{|c|}{ Particle size* } & & \\
\hline & \multicolumn{2}{|c|}{ Large } & \multicolumn{2}{|c|}{ Medium } & \multicolumn{2}{|c|}{ Small } & \multicolumn{2}{|c|}{ Soluble } \\
\hline & Mean & $\mathrm{SE}$ & Mean & $\mathrm{SE}$ & Mean & $\mathrm{SE}$ & Mean & $\mathrm{SE}$ \\
\hline \multicolumn{9}{|l|}{ Rumen digesta: } \\
\hline $\begin{array}{l}\mathrm{DM}(\mathrm{g} / \mathrm{g} \text { total } \mathrm{DM}) \\
\mathrm{Yb} \text {. }\end{array}$ & 0.26 & 0.01 & 0.05 & 0.01 & $0 \cdot 24$ & 0.03 & 0.45 & 0.01 \\
\hline $\mathrm{g} / \mathrm{g}$ total $\mathrm{Yb}$ & 0.26 & 0.03 & 0.09 & 0.02 & 0.58 & 0.03 & 0.06 & 0.02 \\
\hline$\mu \mathrm{g} / \mathrm{g} \mathrm{DM}$ & 112 & $13 \cdot 7$ & 229 & 38.7 & 279 & $39 \cdot 0$ & 18 & $7 \cdot 6$ \\
\hline $\begin{array}{l}\text { Duodenal digesta: } \\
\text { DM (g/g total DM) }\end{array}$ & $0 \cdot 12$ & 0.06 & $0 \cdot 13$ & 0.01 & 0.22 & 0.01 & 0.53 & 0.06 \\
\hline $\mathrm{Yb}:$ & & & & & & & & \\
\hline $\mathrm{g} / \mathrm{g}$ total $\mathrm{Yb}$ & $0 \cdot 13$ & 0.06 & $0 \cdot 19$ & 0.02 & 0.61 & 0.03 & 0.07 & 0.01 \\
\hline$\mu \mathrm{g} / \mathrm{g} \mathrm{DM}$ & 172 & $22 \cdot 8$ & 201 & $29 \cdot 3$ & 416 & $55 \cdot 6$ & 19 & $3 \cdot 1$ \\
\hline Ileal diesta: & & & & & & & & \\
\hline $\mathrm{DM}(\mathrm{g} / \mathrm{g}$ total $\mathrm{DM})$ & 0.09 & 0.02 & $0 \cdot 10$ & 0.01 & $0 \cdot 32$ & 0.02 & 0.49 & 0.01 \\
\hline $\begin{array}{l}\mathrm{Yb}: \\
\mathrm{g} / \mathrm{g} \text { total } \mathrm{Yb}\end{array}$ & 0.05 & 0.01 & 0.09 & 0.02 & 0.79 & 0.01 & 0.07 & 0.00 \\
\hline$\mu \mathrm{g} / \mathrm{g} \mathrm{DM}$ & 196 & $34 \cdot 8$ & 266 & 43.6 & 769 & $17 \cdot 3$ & 42 & $4 \cdot 8$ \\
\hline
\end{tabular}

${ }^{*}$ Large $>1200 \mu \mathrm{m}$, medium $1200-150 \mu \mathrm{m}$, small $<150 \mu \mathrm{m}$.

blank incubations containing no substrate, increased with time, whereas the ammonia concentration decreased. Results showing the effect of the highest level of $\mathrm{Yb}$ on the net changes during a $24 \mathrm{~h}$ incubation are presented in Table 5 .

The distribution of $\mathrm{DM}$ and $\mathrm{Yb}$ between the soluble and particulate matter and within the particulate matter in samples of rumen, duodenal and ileal digesta obtained from sheep receiving the infusions of CrEDTA plus $\mathrm{Yb}$ acetate is shown in Table 6. In all samples of digesta, the DM was approximately equally distributed between the soluble and particulate matter, whereas the $\mathrm{Yb}$ was associated predominantly $(>90 \%)$ with the particulate matter. However, it was not uniformly distributed within the particulate matter and the concentraton increased as particle size decreased. In ileal digesta there was a four-fold difference between 
Table 7. Comparison of 'true' duodenal flows ( $\mathrm{g} / \mathrm{d})$ of dry matter $(D M)$, organic matter $(O M)$ and total nitrogen with the flows based on the individual marker (chromium and ytterbium) concentrations in unrepresentative digesta, either high $(H P)$ or low $(L P)$ in particulate matter, and those derived by reconstitution $(\mathrm{Cr}+\mathrm{Yb})$ of the unrepresentative digesta samples

(Mean values with their standard errors for three sheep)

\begin{tabular}{|c|c|c|c|c|c|c|}
\hline & \multicolumn{2}{|c|}{ DM } & \multicolumn{2}{|c|}{ OM } & \multicolumn{2}{|c|}{ Total N } \\
\hline & Mean & $\mathrm{SE}$ & Mean & SE & Mean & $\mathrm{SE}$ \\
\hline $\begin{array}{l}\text { 'True' flow } \\
\text { HP digesta: }\end{array}$ & 577 & 35.0 & 439 & $24 \cdot 4$ & $28 \cdot 6$ & $1 \cdot 3$ \\
\hline $\mathrm{Cr}_{\mathrm{r}}$ & 660 & $44 \cdot 4$ & 508 & $36 \cdot 3$ & $30 \cdot 6$ & 2.5 \\
\hline $\mathrm{Yb}$ & $554^{*}$ & 39.8 & 426 & $28 \cdot 0$ & $25 \cdot 6^{* * *}$ & 1.5 \\
\hline $\mathrm{Cr}+\mathrm{Yb}$ & 583 & $39 \cdot 4$ & 432 & $28 \cdot 3$ & $26 \cdot 6^{*}$ & 1.7 \\
\hline LP digesta: & & & & & & \\
\hline $\mathrm{Cr}$ & $460^{*}$ & $18 \cdot 0$ & $337^{*}$ & $10 \cdot 2$ & $22 \cdot 5^{*}$ & 0.8 \\
\hline $\mathrm{Yb}$ & $618^{*}$ & $40 \cdot 4$ & 452 & $25 \cdot 5$ & $30 \cdot 2$ & 1.6 \\
\hline $\mathrm{Cr}+\mathrm{Yb}$ & 565 & $30 \cdot 9$ & 436 & 22.7 & $27 \cdot 4$ & 1.2 \\
\hline
\end{tabular}

Statistical significance of difference from 'true' flow: ${ }^{*} P<0.05,{ }^{* *} P<0.01$.

the $\mathrm{Yb}$ concentration of the small- and large-particle fractions compared with a $2 \cdot 5$-fold difference in rumen and duodenal digesta.

The effect of using CrEDTA and Yb acetate as a dual-phase marker system for estimating duodenal flow, when the digesta sample was unrepresentative, is shown in Table 7 in which estimates obtained by reconstitution are compared with those based on the individual marker concentrations in the unrepresentative digesta samples and also with the 'true' flows. To allow direct comparison between the procedures, 'true' flow represents the mean of the flows based on the amounts of $\mathrm{Cr}$ or $\mathrm{Yb}$ actually infused and their respective concentrations in the 'true' digesta, i.e. that from which the unrepresentative digesta samples were prepared, whilst marker infusion rates used in other calculations were derived by multiplying the $\mathrm{Cr}$ or $\mathrm{Yb}$ concentration in the 'true' digesta DM by the 'true' DM flow. Thus, the extent to which the HP and LP digesta samples were unrepresentative is indicated by the amount by which the flows based on the individual markers differed from each other and from the 'true' flows: with the HP digesta, flows based on $\mathrm{Cr}$ were higher and those based on $\mathrm{Yb}$ were lower than the 'true' flows, whereas with the LP digesta, the Cr-based flows were lower and the Yb-based flows higher. Using the dual-phase marker reconstitution procedure, the calculated reconstitution factor, i.e. the number of units of the subsample DM to be added to $(+)$ or removed from (-) one unit of digesta DM was -0.191 (SE 0.0358) for the HP digesta and +0.3385 (SE 0.0310) for the LP digesta. For both types of digesta the reconstituted flows of DM and OM were very similar to the "true' flows, whereas the reconstituted total $\mathrm{N}$ flows tended to be lower than the 'true' flow.

\section{DISCUSSION}

\section{$I A D F$ as a digesta-flow marker}

Naturally occurring internal markers, such as IADF, have the obvious advantage over external markers, such as $\mathrm{Yb}$, in that as integral parts of the feed there is no possibility of any adverse effect on the metabolic, digestive and physiological processes of digestion. Penning \& Johnson (1983) found that with most diets the amount of IADF excreted in faeces tended to be slightly lower than that ingested and, similarly, in the present study the average recovery of IADF in faeces was only $95.9 \%$ of the intake. However, statistical comparison 
of the IADF-based estimates of faecal DM excretion with that determined by total collection and also the comparison of the IADF-based estimates of ileal and duodenal DM flow with those based on $\mathrm{Cr}$ or $\mathrm{Yb}$, suggest that IADF may be a reasonably reliable marker for estimating faecal output and ileal flow, but less reliable for estimating duodenal flow. The lack of agreement between the IADF-based estimates of duodenal flow and those based on either $\mathrm{Cr}$ or $\mathrm{Yb}$ may reflect the analytical problems, in terms of specificity and sensitivity, commonly associated with the gravimetric analysis of internal markers.

\section{$Y b$ acetate as a particulate-phase digesta-flow marker}

$Y b$ analysis. The analysis of $\mathrm{Yb}$ by atomic absorption spectrometry was particularly susceptible to matrix interferences necessitating the use of standards prepared in blank digesta or faeces. Provided this precaution was taken and potassium was included in the extraction acid as an ionization suppressant, the concentration of $\mathrm{Yb}$ obtained in digesta and faeces with an infusion rate of $100 \mathrm{mg} \mathrm{Yb} / \mathrm{kg} \mathrm{DM}$ intake could be reproducibly measured. Since this study was completed, the strong acid used for extracting the ashed samples has been found to cause corrosion of the stainless-steel nebulizer venturi of the atomic absorption spectrometer, and has been replaced by a solution of nitric acid $(20 \mathrm{ml} / \mathrm{l})$ containing $1 \mathrm{mg} \mathrm{K} / \mathrm{ml}$. An alternative procedure for measuring $\mathrm{Yb}$ in faeces in which unashed samples are extracted with EDTA solution has recently been published (Hart \& Polan, 1984).

Marker absorption. The mean faecal recoveries of the infused $\mathrm{Yb}$ and $\mathrm{Cr}$ were $103.9 \%$ and $94.7 \%$ respectively. Absorption of $\mathrm{Cr}$ from the gastrointestinal tract was confirmed by an increase in urinary $\mathrm{Cr}$ excretion, whereas no $\mathrm{Yb}$ was detected in urine. Other workers (e.g.Downes \& McDonald, 1964) have also demonstrated that small amounts of CrEDTA are absorbed from the gastrointestinal tract, and Faichney (1975b) showed that of the total absorption between rumen and faeces, approximately 0.4 was lost in the rumen and 0.2 and 0.4 in the small and large intestine respectively.

Effect of $Y b$ on digestion. Comparison of the amounts of $\mathrm{OM}, \mathrm{N}$ and cellulose flowing at the duodenum and ileum and excreted in the faeces of sheep receiving continuous intraruminal infusions of either CrEDTA or CrEDTA and $\mathrm{Yb}$ acetate suggested that the infusion of $\mathrm{Yb}$ had no effect on the digestive processes occurring in the rumen, small intestine and large intestine. More detailed measurement of the metabolic processes occurring in the rumen in terms of VFA producton, ammonia kinetics and microbial $\mathrm{N}$ synthesis also suggested no effect of infused $\mathrm{Yb}$ on microbial metabolism.

The polyester-bag procedure was used to assess the effect of $\mathrm{Yb}$ on the degradative activity of the rumen micro-organisms by comparing feedstuff degradation rates in the rumen of sheep receiving continuous intraruminal infusions of either CrEDTA or CrEDTA and $\mathrm{Yb}$ acetate. It was also used to assess the effect of $\mathrm{Yb}$ on the susceptibility of the feed to microbial attack by measuring the rate of degradation of feed which had been pre-labelled with different amounts of $\mathrm{Yb}$. Neither microbial degradative activity nor the susceptibility of the feed to microbial degradation was found to be affected by the rates of $\mathrm{Yb}$ addition used in this study. Similarly, in vitro studies using either pre-labelled feed or by addition of $\mathrm{Yb}$ acetate to the incubation mixture showed no effect of $\mathrm{Yb}$ on $\mathrm{OM}$ digestibility nor on VFA and ammonia production during incubaton with rumen fluid. Coleman et al. (1984) also found that the in vitro digestibility of different feeds was not affected by addition of $\mathrm{Yb}$ (up to $625 \mathrm{mg} / \mathrm{kg}$ feed $\mathrm{DM}$ ) to the fermentation mixture. However, the pre-labelling of feeds with $\mathrm{Yb}$ has been found to reduce in vitro digestibility and also rates of degradation when incubated in nylon bags in the rumen (Coleman et al. 1984; Teeter et al. 1984), but at much higher levels of $\mathrm{Yb}$ application ( $>4000 \mu \mathrm{g} / \mathrm{g} \mathrm{DM}$ ) than those used in the present study or than those obtained in the rumen during the infusion of $\mathrm{Yb}$ acetate.

Marker distribution in digesta. Although small amounts of CrEDTA may be associated 
with particulate matter, it is present mainly in the liquid fraction of the digesta (Warner, 1969). $\mathrm{Yb}$, on the other hand, was associated predominantly with particulate matter but was not uniformly distributed.The possibility cannot, at present, be discounted that the higher concentration of $\mathrm{Yb}$ found in the small-particle fraction may, at least in part, be due to the formation of insoluble $\mathrm{Yb}$ salts rather than $\mathrm{Yb}$ binding to small particles. Ruthenium phenanthroline has also been found to be unevenly distributed throughout the particulate matter: in the studies of Mudgal et al. (1982) and Egan et al. (1983) it was associated mainly with the small particles, whereas in the study of Egan \& Doyle (1984) it was present in higher concentrations in the medium than in the small or large particles. In the dual-phase marker reconstitution procedure, digesta are assumed to consist of a fluid phase and particulate phase, with unrepresentative sampling being due to a pereferential selection of one of these phases. Since a small proportion of the $\mathrm{Yb}$ was soluble and also because small particles will be present in the fluid phase, $\mathrm{Yb}$ cannot be considered an ideal particulate-phase marker, in terms of associatiing exclusively with the particulate phase. However, this would not preclude its use with CrEDTA in a dual-phase marker system provided that a greater proportion of the infused $\mathrm{Yb}$ than of the infused $\mathrm{Cr}$ was associated with the particulate phase.

Reconstitution of unrepresentative digesta. The ability of CrEDTA and $\mathrm{Yb}$ acetate to act as a dual-phase marker system was examined using artificially-prepared, unrepresentative samples of duodenal digesta which were enriched either in terms of fluid phase or particulate phase. By so doing the composition of the representative digesta, i.e. the original digesta, and thus the 'true' nutrient flows were known. The reconstitution procedure proved very successful in estimating 'true' DM and OM flow but slightly less good for estimating total $\mathrm{N}$ flow. However, whereas the total $\mathrm{N}$ flows determined by reconstitution of the HP and LP digesta were lower than the 'true' $N$ flow by only 7 and $4 \%$ respectively, estimates of total $\mathrm{N}$ flow based on a single marker concentration in the unrepresentative digesta samples differed from the 'true' flow by as much as $21 \%$, depending on the marker and the nature of the digesta. Faichney (1980) concluded that a single marker was less reliable than a two-marker system in terms of giving valid estimates of flow when the experimental procedure was such that the digesta sampled was not representative of that flowing past the cannula. The dual-phase marker system is dependent on the composition of each of the two phases in the unrepresentative digesta sample and in the subsample prepared from it being the same as that of the corresponding phase in representative digesta. Thus, the small errors in estimating 'true' total $\mathbf{N}$ flow could have arisen if the composition of the 'fluid' phase removed during the preparation of the unrepresentative digesta samples had not been the same as that of the 'fluid' phase removed during the preparation of the subsample.

\section{Conclusion}

Although limited to only one diet, the results of the present study suggest that intraruminally infused $\mathrm{Yb}$ acetate does fulfil the analytical, non-absorbable and non-toxic requirements of a digesta flow marker but does not associate exclusively with the particulate phase of the digesta. However, its affinity for the particulate phase was greater than that of CrEDTA and as such could be used together with CrEDTA in a dual-phase marker system for the reconstitution of unrepresentative digesta samples.

The authors wish to thank Mr D. L. Gale, Mr R. Pilgrim and Mrs A. Oseman for technical assistance and $\mathrm{Mr}$ M. S. Dhanoa for his help with statistical analysis. The Grassland Research Institute is financed through the Agriculture and Food Research Council and the work formed part of a commission from the Ministry of Agriculture, Fisheries and Food. 


\section{REFERENCES}

Beever, D. E., Kellaway, R. C., Thomson, D. J., MacRae, J. C., Evans, C. C. \& Wallace, A. S. (1978). Journal of Agricultural Science, Cambridge 90, 157-163.

Binnerts, W. T., van't Klooster, A. Th. \& Frens, A. M. (1968). Veterinary Record 82, 470.

Canaway, R. J. \& Thomson, D. J. (1977). The Grassland Research Institute Technical Report No. 23. Hurley, Berks.: The Grassland Research Institute.

Christian, K. R. \& Coup, M. R. (1954). New Zealand Journal of Science and Technology 36A, 328-330.

Coleman, S. W., Evans, B. C. \& Horn, G. W. (1984). Journal of Animal Science 58, 979-986.

Crampton, E. W. \& Maynard, L. A. (1938). Journal of Nutrition 15, 387-395.

Crooker, B. A., Clark, J. H. \& Shanks, R. D. (1982). Journal of Nutrition 112, 1353-1361.

Downes, A. M. \& McDonald, I. W. (1964), British Journal of Nutrition 18, 153-162.

Egan, J. K. \& Doyle, P. T. (1984). Australian Journal of Agricultural Research 35, 279-291.

Egan, J. K., Pearce. G. R., Doyle, P. T. \& Thomas, R. (1983). Australian Journal of Agricultural Research 34, 307-315.

Ellis, W. C., Lascano, C., Teeter, R. G. \& Owens, F. N. (1982). In Protein Requirements for Cattle, Misc. Publ. no. 109 , pp. 37-56 [F. N. Owens, editor]. Stillwater, USA: Oklahoma State University.

Engelhardt, W. V. (1974). Tracer Techniques in Tropical Animal Production, pp. 111-124. Vienna: International Atomic Energy Agency.

Evans, C. C., MacRae, J. C. \& Wilson, S. (1977). Joumal of Agricultural Science, Cambridge 89, 17-22.

Faichney, G. J. (1975a). In Digestion and Metabolism in the Ruminant, pp 277-291. [1. W. McDonald and A. C. I. Warner, editors]. Armidale, Australia: The University of New England Publishing Unit.

Faichney, G. J. (1975b), Australian Journal of Agricultural Research, 26, 319-327.

Faichney, G. J. (1980). Journal of Agricultural Science, Cambridge, 94, 313-318.

Gehrke, G. W., Kaiser, F. E. \& Ussary, J. P. (1968). Journal of the Association of Official Analytical Chemists 51, $200-211$.

Hart, S. P. \& Polan. C. E. (1984). Journal of Dairy Science 67, 888-892.

Hartnell, G. F. \& Satter, L. D. (1979). Journal of Animal Science 48, 375-380.

McDougall, E. I. (1948). Biochemical Journal 43, 99-109.

McRae, J. C. (1975). In Digestion and Metabolism in the Ruminant, pp. 261-276 [1. W. McDonald and A. C. I. Warner, editors]. Armidale, Australia: The University of New England Publishing Unit.

Mudgal, V. D., Dixon, R. M., Kennedy, P. M. \& Milligan, L. P. (1982). Journal of Animal Science 54, $1051-1055$.

Penning, P. D. \& Johnson, R. H. (1983). Journal of Agricultural Science, Cambridge 100, 133-138.

Pruden, G., Powlson. D. S. \& Jenkinson, D. S. (1985). Fertilizer Research 6, 205-218.

Siddons, R. C., Beever, D. E. \& Nolan, J. V. (1982). British Journal of Nutrition 48, 377-389.

Tan, T. W., Weston, R. H. \& Hogan, J. P. (1971). International Journal of Applied Radiation and Isotopes 22, 301-308.

Teeter, R. G., Owens, F. N. \& Horn, G. W. (1979). Journal of Animal Science 49, Supp1. 1, 412.

Teeter, R. G., Owens, F. N. \& Mader, T. L. (1984). Journal of Animal Science 58, 465-473.

Tilley, J. M. A. \& Terry, R. A. (1963). Journal of the British Grassland Society 18, 104-111.

Uden, P., Colucci, P. E. \& Van Soest, P. J. (1980). Journal of the Science of Food and Agriculture 31, 625-632.

Warner, A. C. I. (1969). Veterinary Record 81, 441-442.

Weller, R. A., Gray, F. V., Pilgrim, A. F. \& Jones, G. B. (1967). Australian Journal of Agricultural Research 18, 107-118. 